\title{
Echocardiographic predictors of severe heart failure symptoms in hypertrophic cardiomyopathy patients with sinus rhythm Fatih Bayrak*1, Gokhan Kahveci ${ }^{2}$, Muzaffer Degertekin ${ }^{1}$ and Bulent Mutlu ${ }^{3}$
} Address: ${ }^{1}$ Yeditepe University Hospital, Department of Cardiology, Istanbul, Turkey, ${ }^{2}$ Rize State Hospital, Department of Cardiology, Rize, Turkey
and ${ }^{3}$ Kosuyolu Heart and Research Hospital, Department of Cardiology, Istanbul, Turkey

Email: Fatih Bayrak* - dfatihbayrak@yahoo.com; Gokhan Kahveci - drmarist@yahoo.co.uk; Muzaffer Degertekin - mdegertekin@yeditepe.edu.tr; Bulent Mutlu - dr.bmutlu@superonline.com

* Corresponding author

Published: 29 February 2008

Trials 2008, 9:1। doi:10.1/86/1745-62/5-9-II
Received: I December 2007

Accepted: 29 February 2008

This article is available from: http://www.trialsjournal.com/content/9/I/II

(C) 2008 Bayrak et al; licensee BioMed Central Ltd.

This is an Open Access article distributed under the terms of the Creative Commons Attribution License (http://creativecommons.org/licenses/by/2.0), which permits unrestricted use, distribution, and reproduction in any medium, provided the original work is properly cited.

\begin{abstract}
Background: Symptoms in hypertrophic cardiomyopathy $(\mathrm{HC})$ appear to be caused by diastolic dysfunction, myocardial ischemia, left ventricle (LV) outflow obstruction, and atrial fibrillation. However, clinical deterioration and severe heart failure symptoms can be observed in patients without any of these factors. Thus, the aim of this study is to determine the echocardiographic predictors of severe heart failure symptoms in patients with $\mathrm{HC}$.

Methods and results: $86 \mathrm{HC}$ patients were compared according to symptomatic status. Patients with severe heart failure symptoms were older, preponderantly female, had more often LV outflow obstruction and mitral regurgitation, longer $E$ wave deceleration time (EDt), higher E/Ea ratios and lower LV tissue Doppler (TD) velocities when compared to rest of the patients. LV outflow obstruction ( $r=0.43, R^{2}=0.19, p<0.0001$ ), LV lateral mitral annular systolic TD velocity (LMSa) $\left(r=0.5 I, R^{2}=0.26, p<0.006\right)$ and EDt $\left(r=0.55, R^{2}=0.30, p<0.027\right)$ were found to be the independent predictors for severe heart failure symptoms in forward stepwise regression.

Conclusion: In HCM patients with sinus rhythm and normal LV systolic function, LMSa, EDt and LV outflow obstruction are independent predictors of heart failure symptoms. Diastolic dysfunction determined with EDt, occult systolic dysfunction which is detected with TD analysis, and afterload increase as result of LV outflow obstruction seem to be the main echocardiographic factors affecting symptomatic status in HCM patients with sinus rhythm and normal systolic function.
\end{abstract}

\section{Background}

Hypertrophic cardiomyopathy (HC) is a complex genetic cardiac disorder with heterogeneous clinical course and expression [1-3]. Exertional dyspnea and disability usually occur in the presence of preserved systolic function and a non-dilated left ventricle (LV) $[1,4]$. Symptoms appear to be caused in large measure by diastolic dysfunction [5-8], myocardial ischemia [9-15], outflow obstruc- tion associated with mitral regurgitation $[16,17]$ and atrial fibrillation [18]. Of these parameters, which predicts heart failure symptoms best is unclear. Besides, clinical deterioration may be observed even in HC patients without any of these factors $[1,2]$. Thus, the aim of this study is to determine the echocardiographic predictors of severe heart failure symptoms in patients with HC. 


\section{Methods \\ Study population}

One hundred and ten consecutive patients who were admitted to our echocardiography laboratory and diagnosed as HC were included in the study. The diagnosis of HC was based on the demonstration of a hypertrophied, non-dilated left ventricle (LV) (wall thickness of at least $15 \mathrm{~mm}$ ) by 2-dimensional echocardiography in the absence of another cardiac or systemic disease capable of producing a similar degree of hypertrophy [3]. A detailed clinical evaluation was performed for each patient after the echocardiographic examination.

Functional capacity was assessed according to the New York Heart Association (NYHA) classification by one investigator without knowledge of the laboratory results. Heart failure symptoms are defined by exertional dyspnea and functional limitation (with or without chest pain) independent of whether episodes of impaired consciousness (syncope or presyncope) have occurred [19,20]. Ten patients with co-morbid cardiovascular, pulmonary, renal conditions and 14 patients with LV systolic dysfunction (LV ejection fraction $<50 \%$ ), previous septal myectomy, previous alcohol septal ablation and atrial fibrillation were excluded from the study (remaining 86 patients formed the study population). The study complies with the Declaration of Helsinki, was approved by the local ethical committee and each patient gave written informed consent.

\section{Echocardiographic analysis}

A complete echocardiographic examination was performed with a Vivid Five System (GE, Vingmed Ultrasound, Horten, Norway) in each patient at rest by a single blinded observer. LV hypertrophy was assessed with 2dimensional echocardiography according to published criteria [3]. The greatest thickness measured at any site in the LV wall was considered to represent LV maximal wall thickness [21]. Peak instantaneous LV outflow gradient was estimated under basal conditions with continuous wave Doppler [17].

2-dimensional measurements included LV end-diastolic and end-systolic diameters, posterior wall thickness, interventricular septal thickness, and LV ejection fraction [22]. Mitral inflow Doppler was measured in standard fashion to determine peak E- and A-wave velocities, deceleration time of the transmitral E wave, and isovolumic relaxation time [23]. Mitral regurgitation was assessed by color Doppler velocity mapping as the ratio of the area of the color jet divided by the maximum LA area [24]. Apical 4-chamber views of color 2-dimensional tissue Doppler (TD) images were acquired during end-expiration at a frame rate of 100 to 140 frames per second to minimize background noise. TD digital data were stored and analyzed offline (EchoPac, GE Vingmed). Sample volumes were placed in the inner half of the myocardium on the basal segments of the left ventricle at the septal, lateral walls and of the right ventricle at the lateral wall adjacent to the atrio-ventricular valve hinge points in the apical 4-chamber view [25]. Systolic (Sa), early diastolic (Ea), and late diastolic (Aa) TD velocities were measured for all segments and subsequently averaged over 3 cardiac cycles in accordance with previous reports [23,25]. Transmitral E/ Ea ratios of LV (lateral and septal) were calculated for each patient.

\section{Statistical analysis}

Statistical analysis was performed with SPSS 11.5 (SPSS, Chicago, Illinois, USA) software. Data are expressed as mean \pm SD. Relevant relationships were tested by $\chi^{2}$ analysis for proportions and unpaired Student's $t$ test for continuous variables. For comparison of continuous echocardiographic variables in different NYHA functional classes, one way analysis of variance (ANOVA) was used. Forward stepwise regression was performed to determine predictors of severe heart failure symptoms. A probability value $<0.05$ was required for retention within the final stepwise regression model. Statistical significance was taken as $p<0.05$.

\section{Results \\ Patient characteristics}

The pattern of LV hypertrophy was asymmetric septal in 76 patients, apical in 4 patients, concentric in 5 patients and isolated posterior wall hypertrophy in 1 patient. Forty-three patients (50\%) had basal resting left ventricular outflow tract obstruction with a peak gradient $>30$ $\mathrm{mmHg}$. Thirty patients had a positive family history of $\mathrm{HC}$ (36\%) and 18 patients had a history of sudden death in first degree relatives (22\%). At admission 32 (37\%) of the patients were asymptomatic (NYHA class I), 37 (43\%) had mild symptoms (NYHA class II) and 17 (20\%) had severe symptoms (NYHA class III-IV).

NYHA class of patients correlated with various echocardiographic and clinical parameters such as age $(\mathrm{p}=0.02, \mathrm{R}$ : $0.34)$, left atrium diameter $(\mathrm{p}=0.04, \mathrm{R}$ : 0.22), E wave deceleration time $(\mathrm{p}=0.001, \mathrm{R}: 0.41)$, LV outflow obstruction ( $\mathrm{p}=0.001, \mathrm{R}: 0.37)$, and LV lateral mitral annular systolic tissue Doppler velocity (LMSa) $(\mathrm{p}=$ 0.001, R: -0.36).

The comparison of demographic and echocardiographic parameters including TD velocities of HC patients with and without severe heart failure symptoms (NYHA class III vs. NYHA class III-IV) is presented in Table 1. Patients with severe heart failure symptoms were older, preponderantly female, had more often LV outflow obstruction and mitral regurgitation, longer isovolumetric relaxation 
Table I: Comparison of demographic, clinical and echocardiographic variables of HC patients with and without severe heart failure symptoms (NYHA class I-II vs. NYHA class II-IV)

\begin{tabular}{|c|c|c|c|}
\hline Variable & Severe symptom $+(n=17)$ & Severe symptom $-(n=69)$ & $\mathbf{p}$ \\
\hline \multicolumn{4}{|l|}{ Demographics } \\
\hline Female gender & $10(59 \%)$ & $17(25 \%)$ & 0.003 \\
\hline Age (years) & $54 \pm 17$ & $43 \pm 16$ & 0.03 \\
\hline Blood pressure, $\mathrm{mmHg}$ & $116 / 67$ & $1 \mid 4 / 67$ & NS \\
\hline \multicolumn{4}{|l|}{ Medical therapy } \\
\hline Beta-blockers & $14(86 \%)$ & 57 (84\%) & NS \\
\hline Calcium channel blockers & $2(13 \%)$ & $10(15 \%)$ & NS \\
\hline \multicolumn{4}{|l|}{ Echocardiographic findings } \\
\hline Left atrium, $\mathrm{mm}$ & $46 \pm 6$ & $44 \pm 8$ & NS \\
\hline LV end-diastolic diameter, mm & $38 \pm 8$ & $42 \pm 5$ & NS \\
\hline LV end-systolic diameter, $\mathrm{mm}$ & $21 \pm 5$ & $24 \pm 5$ & NS \\
\hline Maximal wall thickness, $\mathrm{mm}$ & $25 \pm 6$ & $24 \pm 5$ & NS \\
\hline Posterior wall diastolic thickness, $\mathrm{mm}$ & $16 \pm 9$ & $13 \pm 5$ & NS \\
\hline Mitral E velocity, $\mathrm{m} / \mathrm{s}$ & $0.72 \pm 0.2$ & $0.77 \pm 0.2$ & NS \\
\hline Mitral A velocity, m/s & $0.88 \pm 0.3$ & $0.80 \pm 0.3$ & NS \\
\hline E deceleration time, $\mathrm{ms}$ & $267 \pm 61$ & $212 \pm 76$ & 0.004 \\
\hline IVRT, ms & $113 \pm 29$ & $108 \pm 30$ & NS \\
\hline LV ejection fraction, (\%) & $75 \pm 10$ & $76 \pm 8$ & NS \\
\hline LV outflow obstruction, n (\%) & $16(82 \%)$ & $29(42 \%)$ & 0.0001 \\
\hline \multicolumn{4}{|l|}{ Tissue Doppler velocities } \\
\hline E/Ea (septal) & $33 \pm 24$ & $24 \pm 17$ & 0.03 \\
\hline $\mathrm{E} / \mathrm{Ea}$ (lateral mitral) & $33 \pm 32$ & $18 \pm 16$ & 0.004 \\
\hline Lateral mitral $\mathrm{Ea}, \mathrm{cm} / \mathrm{s}$ & $3.2 \pm 1.4$ & $4.5 \pm 2.5$ & 0.007 \\
\hline Lateral mitral $\mathrm{Aa}, \mathrm{cm} / \mathrm{s}$ & $4.0 \pm 2.3$ & $5.4 \pm 2.9$ & 0.05 \\
\hline Lateral mitral $\mathrm{Sa}, \mathrm{cm} / \mathrm{s}$ & $3.1 \pm 1.4$ & $4.7 \pm 1.9$ & 0.001 \\
\hline Septal mitral Ea, cm/s & $2.8 \pm 1.5$ & $3.5 \pm 1.9$ & NS \\
\hline Septal mitral $\mathrm{Aa}, \mathrm{cm} / \mathrm{s}$ & $4.7 \pm 1.9$ & $5.5 \pm 1.9$ & NS \\
\hline Septal mitral Sa, cm/s & $3.7 \pm 1.3$ & $4.5 \pm 1.4$ & 0.03 \\
\hline Lateral tricuspid $\mathrm{Ea}, \mathrm{cm} / \mathrm{s}$ & $6.7 \pm 2.5$ & $7.7 \pm 3.0$ & NS \\
\hline Lateral tricuspid $\mathrm{Aa}, \mathrm{cm} / \mathrm{s}$ & $8.8 \pm 3.5$ & $10.0 \pm 3.8$ & NS \\
\hline Lateral tricuspid $\mathrm{Sa}, \mathrm{cm} / \mathrm{s}$ & $9.7 \pm 1.9$ & $10.2 \pm 3.1$ & NS \\
\hline
\end{tabular}

IVRT indicates isovolumetric relaxation time; LV, left ventricle, NS; non significant.

Severe symptom + is used for NYHA class III-IV patients, severe symptom - for NYHA class I-II patients.

times, higher E/Ea ratios and lower TD velocities of LV when compared to patients without heart failure symptoms. Medical therapies of the patients with and without severe heart failure symptoms were similar.

\section{Predictors of severe heart failure symptoms}

Table 2 shows the results of univariate and multivariable analyses for prediction of severe heart failure symptoms. LV outflow obstruction $\left(\mathrm{r}=0.43, \mathrm{R}^{2}=0.19, \mathrm{p}<0.0001\right)$, LV lateral mitral annular systolic tissue Doppler velocity (LMSa) $\left(\mathrm{r}=0.51, \mathrm{R}^{2}=0.26, \mathrm{p}<0.006\right)$ and E wave deceleration time $(\mathrm{EDt})\left(\mathrm{r}=0.55, \mathrm{R}^{2}=0.30, \mathrm{p}<0.027\right)$ were found to be the independent predictors for severe heart failure symptoms in forward stepwise regression.

LMSa correlated with various echocardiographic and clinical parameters such as left atrium diameter $(\mathrm{p}=0.004, \mathrm{R}$ : -0.30), maximal wall thickness ( $\mathrm{p}=0.001, \mathrm{R}:-0.36)$, and NYHA functional class ( $\mathrm{p}=0.001, \mathrm{R}:-0.36)$.
Table 2: Univariate and multivariate relations for prediction of heart failure symptoms

\begin{tabular}{lccccc}
\hline & Univariate & \multicolumn{3}{c}{ Multivariable } \\
\hline & F value & $\mathbf{p}$ & $\mathbf{R}^{\mathbf{2}}$ & wald & $\mathbf{p}$ \\
\hline Age & 5.79 & 0.018 & $\ldots$ & $\ldots$ & $\mathrm{NS}$ \\
Female gender & 7.13 & 0.009 & $\ldots$ & $\ldots$ & $\mathrm{NS}$ \\
LV outflow obstruction & 18.5 & 0.0001 & 0.19 & 9.1 & $0.000 \mathrm{I}$ \\
Mitral regurgitation & 15.4 & 0.0001 & $\ldots$ & $\ldots$ & $\mathrm{NS}$ \\
Left atrium diameter & 1.3 & 0.25 & $\ldots$ & $\ldots$ & $\mathrm{NS}$ \\
Maximum wall thickness & 0.3 & 0.50 & $\ldots$ & $\ldots$ & $\mathrm{NS}$ \\
E wave deceleration time & 7.1 & 0.009 & 0.30 & 4.7 & 0.027 \\
Lateral mitral Ea, cm/s & 4.1 & 0.045 & $\ldots$ & $\ldots$ & $\mathrm{NS}$ \\
Lateral mitral Aa, cm/s & 3.2 & 0.07 & $\ldots$ & $\ldots$ & $\mathrm{NS}$ \\
Lateral mitral $\mathrm{Sa}, \mathrm{cm} / \mathrm{s}$ & 8 & 0.006 & 0.26 & 6.3 & 0.006 \\
Septal mitral Sa, cm/s & 4.1 & 0.045 & $\ldots$ & $\ldots$ & $\mathrm{NS}$ \\
E/Ea (septal) & 3.7 & 0.05 & $\ldots$ & $\ldots$ & $\mathrm{NS}$ \\
E/Ea (lateral mitral) & 6.4 & 0.01 & $\ldots$ & $\ldots$ & $\mathrm{NS}$ \\
\end{tabular}

LV indicates left ventricle; NS, non-significant 
EDt correlated with age ( $\mathrm{p}=0.01, \mathrm{R}: 0.27)$, NYHA functional class ( $\mathrm{p}=0.0001, \mathrm{R}: 0.39)$, isovolumetric relaxation time ( $\mathrm{p}=0.02, \mathrm{R}: 0.26)$.

EDt gets longer $(188 \pm 55 \mathrm{~ms}$ for class I vs. $233 \pm 86 \mathrm{~ms}$ for class II vs. $267 \pm 61 \mathrm{~ms}$ class III-IV, $\mathrm{p}<0.001)$ and LMSa decreases $(5.1 \pm 2.0 \mathrm{~cm} / \mathrm{s}$ for class I vs. $4.3 \pm 1.7 \mathrm{~cm} /$ $\mathrm{s}$ for class II vs. $3.1 \pm 1.4 \mathrm{~cm} / \mathrm{s}$ class III-IV, $\mathrm{p}<0.002)$ with increasing NYHA functional class (Figures 1 and 2).

\section{Effect of LV outflow obstruction on demographic and echocardiographic variables}

HC patients with LV outflow obstruction had significantly smaller left ventricle cavities, thicker posterior walls, larger left atrium diameters, longer E wave deceleration times, more often mitral regurgitation and more often severe heart failure symptoms than patients without obstruction. TD velocities of left and right ventricle tended to be lower in HC patients with LV outflow obstruction when compared to patients without obstruction, but that did not reach statistical significance (except lateral mitral Ea).

In 43 patients without LV outflow obstruction, only three patients had severe heart failure symptoms. Severely symptomatic non-obstructive patients had significantly larger left atrium diameters $(5.1 \pm 0.3 \mathrm{~cm}$ vs. $4.1 \pm 0.6 \mathrm{~cm}$, $\mathrm{p}<0.009)$ and lower basal septal Ea velocities $(1.4 \pm 0.8$ $\mathrm{cm} / \mathrm{s}$ for class I vs. $3.8 \pm 2 \mathrm{~cm} / \mathrm{s}$ ) when compared to the rest of the non-obstructive HC patients. Because of the low number of severely symptomatic patients in non-obstructive group, no further statistical analyses were performed.

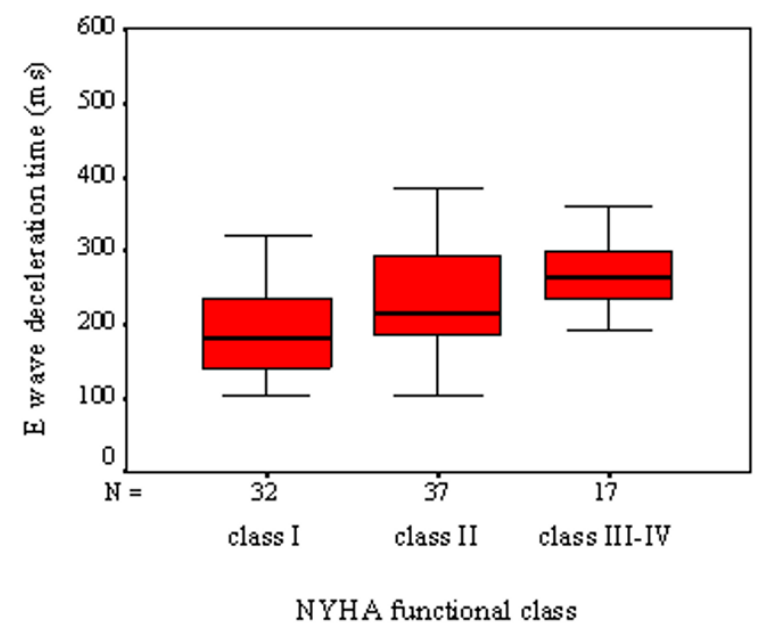

Figure I

Comparison of $E$ wave deceleration time of severely symptomatic HC patients with the rest of the group $(p<0.00 \mathrm{I})$.

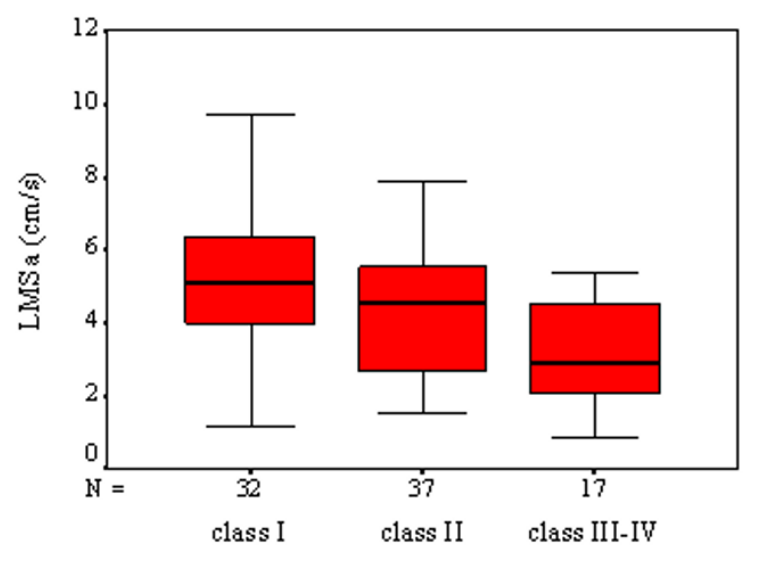

NYHA functional class

Figure 2

Comparison of left ventricle lateral mitral annular systolic tissue Doppler velocity (LMSa) of severely symptomatic HC patients with the rest of the group $(p<0.002)$.

\section{Discussion}

In the present study, we found that NYHA functional class of the HC patients correlated with various echocardiographic and clinical parameters such as age, left atrium diameter, E wave deceleration time (EDt), LV lateral mitral annular systolic tissue Doppler velocity (LMSa), and LV outflow obstruction. Besides these findings, we have shown that EDt, LMSa, and LV outflow obstruction independently predict the presence of severe heart failure symptoms in HC patients with sinus rhythm and normal LV ejection fraction. LMSa is lower and EDt is longer in patients with higher NYHA class which reflects disease severity.

In HC patients, limiting symptoms of exertional dyspnea typically occur in the presence of preserved systolic function and a non-dilated LV $[1,4]$. Symptoms appear to be caused mainly by diastolic dysfunction [5-8], myocardial ischemia [9-15], outflow obstruction associated with mitral regurgitation [16,17], and atrial fibrillation [18]. On the other side, Chikamori and colleagues suggest that there are different mechanisms of exercise limitation in hypertrophic cardiomyopathy: in patients with a left ventricular outflow gradient at rest, the main determinants of exercise limitation were impaired left ventricular and left atrial systolic performance; in those without a gradient, however, diastolic function at rest was a more important factor in the limitation of exercise performance [26]. In our study, non-obstructive severely symptomatic patients $(n=3)$ had significantly larger left atrium diameters and lower basal septal Ea velocities when compared with the rest of the non-obstructive patients, but because of the 
low number of patients, we can not make any further comments. In view of all these information, it still seems to be controversial whether or not left ventricular diastolic pressure and function at rest are major determinants of exercise capacity in hypertrophic cardiomyopathy, and the true mechanism of exercise limitation remains unclear.

Doppler echocardiographic evaluation of trans-mitral LV filling velocities is widely used to assess LV diastolic function. However, most studies $[27,28]$ have failed to show significant correlations between Doppler- derived transmitral flow velocities and exercise capacity in patients with HC. Conventional echocardiographic Doppler indexes may be unreliable for assessment of LV diastolic function in such patients, probably because of their dependence on loading conditions [29-31]. In our study, EDt was an independent predictor of severe symptoms but its value may be limited because of its dependence in loading conditions, and as a result tissue Doppler variables and LV outflow obstruction may be more valuable in that respect.

Similar to our findings, the association between tissue Doppler variables and heart failure symptoms were demonstrated in several trials. Tissue Doppler derived indexes were found to be correlated with exercise capacity and NYHA functional class in HC patients [32,33], but these studies have evaluated the relation between symptoms and diastolic tissue Doppler variables. In our study, for the first time we have demonstrated that systolic tissue Doppler variables are also of importance in respect of predicting heart failure symptoms. The decreased LMSa in symptomatic HC patients may be explained with progressive remodelling and/or fibrosis of left ventricle over time and may be of value as a predictor of occult systolic dysfunction and impending heart failure symptoms.

We did not observe statistically significant differences in systolic and diastolic TD velocities of left and right ventricle (except lateral mitral Ea) between HC patients with and without LV outflow obstruction. These findings were in accordance with previously published studies [34,35].

Assessment of symptom severity may be highly subjective, encumbered by the heterogeneous presentation of the patients. So, EDt and LMSa may guide the clinician in deciding the severity of the disease and in making the decision for further invasive therapies. Patients with LV outflow obstruction, longer EDt, and lower LMSa seem to be under risk of clinical deterioration as they have more severe symptoms, but this data will have to be validated with further prognostic studies.
The study was conducted at a tertiary referral cardiac hospital; as a result high prevalence of severe heart failure symptoms (20\%) and LV outflow obstruction (50\%) were observed.

The small number of HC patients is a weakness of our study, and also we can not exclude the possibility that some patients may develop advanced symptoms of heart failure later in life. NYHA classification, as a subjective measurement of functional disability, may not always reflect functional status accurately in HC patients, but in previous studies, metabolic stress testing in a large HC cohort showed peak oxygen consumption to be significantly related to NYHA class [36].

\section{Conclusion}

For HC patients, LMSa, EDt and LV outflow obstruction are independent predictors of heart failure symptoms. These findings suggest that diastolic dysfunction determined with EDt, occult systolic dysfunction which is detected with tissue Doppler analysis, and afterload increase as result of LV outflow obstruction may be the main echocardiographic factors affecting symptomatic status in HC patients with sinus rhythm and normal systolic function.

\section{Competing interests}

The authors declare that they have no competing interests.

\section{Authors' contributions}

FB carried out the echocardiographic studies, participated in the design of the study and drafted the manuscript. GK carried out the carried out the echocardiographic studies and drafted the manuscript. MD participated in the design of the study and performed the statistical analysis. BM conceived of the study, and participated in its design and coordination and helped to draft the manuscript. All authors read and approved the final manuscript.

\section{Consent}

Written informed consent was obtained from all patients for publication of manuscript. Copies of the written consents are available for review by the Editor-in-Chief of this journal.

\section{Acknowledgements}

We would like to thank Ertan Demirtas for his critical contribution to the interpretation of the study data. None of the authors had a source of funding.

\section{References}

I. Maron BJ, McKenna WJ, Danielson GK, Kappenberger LJ, Kuhn HJ, Seidman CE, Shah PM, Spencer WH 3rd, Spirito P, Ten Cate FJ, Wigle ED, Task Force on Clinical Expert Consensus Documents: ACCI ESC Clinical expert document on hypertophic cardiomyopathy: a report of American College of Cardiology Foundation Task Force on Clinical Expert Consensus Documents 
and European Society of Cardiology Committee for Practice Guidelines. J Am Coll Cardiol 2003, 42:1687-I7I3.

2. Maron BJ: Hypertrophic cardiomyopathy: a systematic review. JAMA 2002, 287:1308-I320.

3. Klues HG, Schiffers A, Maron BJ: Phenotypic spectrum and patterns of left ventricular hypertrophy in hypertrophic cardiomyopathy: morphologic observations and significance as assessed by two dimensional echocardiography in 600 patients. J Am Coll Cardiol 1995, 26: 1699-I708.

4. Frenneaux MP, Porter A, Caforio AL, Odawara H, Counihan PJ, McKenna WJ: Determinants of exercise capacity in hypertrophic cardiomyopathy. J Am Coll Cardiol I989, I3:I52 I-I 526.

5. Briguori C, Betocchi S, Romano M, Manganelli F, Angela Losi M, Ciampi Q, Gottilla R, Lombardi R, Condorelli M, Chiariello M: Exercise capacity in hypertrophic cardiomyopathy depends on left ventricular diastolic function. Am J Cardiol 1999, 84:309-3। 5 .

6. Lele SS, Thomson HL, Seo H, Belenkie I, McKenna WJ, Frenneaux MP: Exercise capacity in hypertrophic cardiomyopathy. Role of stroke volume limitation, heart rate, and diastolic filling characteristics. Circulation 1995, 92:2886-2894.

7. Spirito P, Maron BJ, Bonow RO, Epstein SE: Severe functional limitation in patients with hypertrophic cardiomyopathy and only mild localized left ventricular hypertrophy. J Am Coll Cardiol 1986, 8:537-544.

8. Spirito $P$, Maron BJ: Relation between extent of left ventricular hypertrophy and diastolic filling abnormalities in hypertrophic cardiomyopathy. J Am Coll Cardiol 1990, I5:808-8I3.

9. Cecchi F, Olivotto I, Gistri R, Lorenzoni R, Chiriatti G, Camici PG: Coronary microvascular dysfunction and prognosis in hypertrophic cardiomyopathy. N Engl J Med 2003, 349: I027-1035.

10. Grover-McKay M, Schwaiger M, Krivokapich J, Perloff JK, Phelps ME, Schelbert HR: Regional myocardial blood flow and metabolism at rest in mildly symptomatic patients with hypertrophic cardiomyopathy. I Am Coll Cardiol 1989, 13:3 I7-324.

II. Krams R, Kofflard MJ, Duncker DJ, Von Birgelen C, Carlier S, Kliffen $M$, Ten Cate FJ, Serruys PW: Decreased coronary flow reserve in hypertrophic cardiomyopathy is related to remodeling of the coronary microcirculation. Circulation 1998, 97:230-233.

12. Nienaber CA, Gambhir SS, Mody FV, Ratib O, Huang SC, Phelps ME, Schelbert HR: Regional myocardial blood flow and glucose utilization in symptomatic patients with hypertrophic cardiomyopathy. Circulation 1993, 87: I580-1590.

13. O'Gara PT, Bonow RO, Maron BJ, Damske BA, Van Lingen A, Bacharach SL, Larson SM, Epstein SE: Myocardial perfusion abnormalities in patients with hypertrophic cardiomyopathy: assessment with thallium-20I emission computed tomography. Circulation 1987, 76:12|4-1223.

14. Takata J, Counihan PJ, Gane JN, Doi Y, Chikamori T, Ozawa T, McK enna WJ: Regional thallium-20I washout and myocardial hypertrophy in hypertrophic cardiomyopathy and its relation to exertional chest pain. Am J Cardiol 1993, 72:2 I I-2I7.

15. Schwartzkopff B, Mundhenke M, Strauer BE: Alterations of the architecture of subendocardial arterioles in patients with hypertrophic cardiomyopathy and impaired coronary vasodilator reserve: a possible cause for myocardial ischemia. J Am Coll Cardiol 1998, 31:1089-1096.

16. Wigle ED, Sasson Z, Henderson MA, Ruddy TD, Fulop J, Rakowski H, Williams WG: Hypertrophic cardiomyopathy. The importance of the site and the extent of hypertrophy. A review. Prog Cardiovasc Dis 1985, 28: I-83.

17. Maron MS, Olivotto I, Betocchi S, Casey SA, Lesser JR, Losi MA, Cecchi F, Maron BJ: Effect of left ventricular outflow tract obstruction on clinical outcome in hypertrophic cardiomyopathy. $\mathrm{N}$ Engl J Med 2003, 348:295-303.

18. Olivotto I, Cecchi F, Casey SA, Dolara A, Traverse JH, Maron BJ: Impact of atrial fibrillation on the clinical course of hypertrophic cardiomyopathy. Circulation 200I, 104:2517-24.

19. Wigle ED, Rakowski H, Kimball BP, Williams WG: Hypertrophic cardiomyopathy: clinical spectrum and treatment. Circulation 1995, 92:1680-1692.

20. Maron BJ, Spirito P: Implications of left ventricular remodeling in hypertrophic cardiomyopathy. Am J Cardiol 1998, 81:1339-1344.

21. Spirito P, Bellone P, Harris KM, Bernabo P, Bruzzi P, Maron BJ: Magnitude of left ventricular hypertrophy predicts the risk of sudden death in hypertrophic cardiomyopathy. N Engl J Med 2000, 342:1778-1785.

22. Ikeda H, Maki S, Yoshida N, Murohara T, Adachi H, Koga Y, Imaizumi $\mathrm{T}$ : Predictors of death from congestive cardiac failure in hypertrophic cardiomyopathy. Am J Cardiol I999, 83: I 280-I 283.

23. Nagueh SF, Bachinski LL, Meyer D, Hill R, Zoghbi WA, Tam JW, Quiñones MA, Roberts R, Marian AJ: Tissue Doppler imaging consistently detects myocardial abnormalities in patients with hypertrophic cardiomyopathy and provides a novel means for an early diagnosis before and independently of hypertrophy. Circulation 200I, 104:128-130.

24. Helmcke F, Nanda NC, Hsiung MC, Soto B, Adey CK, Goyal RG, Gatewood RP Jr: Color Doppler assessment of mitral regurgitation with orthogonal planes. Circulation 1987, 75:175-I83.

25. Patel R, Nagueh SF, Tsybouleva N, Abdellatif M, Lutucuta S, Kopelen HA, Quinones MA, Zoghbi WA, Entman ML, Roberts R, Marian AJ: Simvastatin induces regression of cardiac hypertrophy and fibrosis and improves cardiac function in a transgenic rabbit model of human hypertrophic cardiomyopathy. Circulation 200I, 104:317-324.

26. Chikamori T, Counihan PJ, Doi YL, Takata J, Stewart JT, Frenneaux MP, McKenna WJ: Mechanisms of exercise limitation in hypertrophic cardiomyopathy. I Am Coll Cardiol 1992, 19:507-5 I2.

27. Nishimura RA, Appleton CP, Redfield MM, Ilstrup DM, Holmes DR Jr, Tajik AJ: Noninvasive Doppler echocardiographic evaluation of left ventricular filling pressures in patients with cardiomyopathies: a simultaneous Doppler echocardiographic and cardiac catheterization study. I Am Coll Cardiol 1996, 28:1226-1233.

28. Nagueh SF, Lakkis NM, Middleton KJ, Spencer WH 3rd, Zoghbi WA, Quinones MA: Doppler estimation of left ventricular filling pressures in patients with hypertrophic cardiomyopathy. Circulation 1999, 99:254-26I.

29. Thomas JD, Weyman AE: Echo Doppler evaluation of left ventricular diastolic function: physics and physiology. Circulation 1991, 84:977-990.

30. Choong CY, Herrmann HC, Weyman AE, Fifer MA: Preload dependence of Doppler-derived indices of left ventricular diastolic function in humans. J Am Coll Cardiol 1987, 10:800-8I8

31. Stoddard MF, Pearson AC, Kern MJ, Ratcliff J, Mrosek DG, Labovitz AJ: Influence of alteration in preload on the pattern of left ventricular diastolic filling assessed by Doppler echocardiography in humans. Circulation 1989, 79:1226-1236.

32. Ha JW, Cho JR, Kim JM, Ahn JA, Choi EY, Kang SM, Rim SJ, Chung N: Tissue Doppler-derived indices predict exercise capacity in patients with apical hypertrophic cardiomyopathy. Chest 2005, I 28:3428-3433.

33. Matsumura Y, Elliott PM, Virdee MS, Sorajia P, Doi Y, McKenna W]: Left ventricular diastolic function assessed using Doppler tissue imaging in patients with hypertrophic cardiomyopathy: relation to symptoms and exercise capacity. Heart 2002, 87:247-25।

34. Cardim N, Torres D, Morais H, Candido A, Duarte R, Longo S, Ferreira T, Pereira A, Gouveia A, Reis RP, Correia JM: Tissue Doppler imaging in hypertrophic cardiomyopathy: impact of intraventricular obstruction on longitudinal left ventricular function. Rev Port Cardiol 2002, 21:27I-297.

35. Barac I, Upadya S, Pilchik R, Winson G, Passick M, Chaudhry FA, Sherrid MV: Effect of obstruction on longitudinal left ventricular shortening in hypertrophic cardiomyopathy. J Am Coll Cardiol 2007, 49: | 203-|2|I.

36. Sharma S, Elliott P, Whyte G, Jones S, Mahon N, Whipp B, McKenna W]: Utility of cardiopulmonary exercise in the assessment of clinical determinants of functional capacity in hypertrophic cardiomyopathy. Am J Cardiol 2000, 86:162-I68. 